\title{
Design based on reliability of naval multilayer fiber composite panels using evolutionary algorithms and stochastic structural mechanics
}

Diseño basado en confiabilidad de paneles navales fabricados en compuestos reforzados con fibras utilizando algoritmos evolutivos y mecánica estructural estocástica

\author{
Jairo F. Useche, Ph.D ${ }^{1}$ \\ Guillermo Giraldo, M.E. ${ }^{2}$
}

\begin{abstract}
The complexity of sea wave loads and the number of design variables involved in the design of laminated composites for naval applications makes this a challenging problem. Traditional methodologies for engineering design and analysis are not suitable to deal with these kinds of design problems. This work presents a methodology based on evolutionary algorithms and stochastic structural mechanics to design high-reliability naval multilayer composite structural panels.. The mechanical response of structural panels was modeled by using the Multilayer First Order Shear Deformable Plate Theory and the Finite Element Method. Sea wave loads were modeled as stochastic dynamic loads by using the Simulation Based Reliability Analysis approach. The structural reliability of the panel, as a function of the composite ply's fiber direction, was considered a design variable. In order to maximize the structural reliability, an optimization methodology based on Genetic Algorithms was proposed. For the design process, a computational code using FORTRAN ${ }^{\bullet}$ and the OpenMP ${ }^{\bullet}$ library for parallel computing was developed. The proposed methodology was applied to the design of composite naval panels and results were compared to those obtained through traditional design methodologies. The results show increased reliability of the panels in all cases analyzed. The proposed methodology is, thus, shown as a reliable engineering tool to optimize the structural performance of existing designs.
\end{abstract}

Key words: naval composite panels, reliability design, simulation-based reliability analysis, genetic algorithms, optimization, finite element method.

\section{Resumen}

La complejidad de las cargas de las olas del mar y el número de variables de diseńo que intervienen en el diseńo de compuestos laminados para aplicaciones navales hacen de éste un problema difícil. Las metodologías tradicionales de ingeniería de diseńo y análisis no son adecuadas para tratar este tipo de problemas de diseńo. En este trabajo, una metodología basada en algoritmos evolutivos y mecánica estructural estocástica para el diseńo de paneles estructurales navales compuestos multicapa de alta confiabilidad, es presentada. La respuesta mecánica de paneles estructurales se modeló usando la teoría de Placa Multicapa Flexible a Cortante de Primer Orden y el Método de los Elementos Finitos. Cargas de las olas de mar se modelaron como cargas dinámicas estocásticas utilizando el enfoque de simulación basado en análisis de confiabilidad. La confiabilidad estructural del panel, en función de la dirección de las fibras de las capas de material compuesto, se consideró como variable de diseño. Con el fin de maximizar la confiabilidad estructural, una metodología de optimización basada en algoritmos genéticos, se propuso. Para el proceso de diseño, un código computacional usando FORTRAN ${ }^{\circledR}$ y la biblioteca ${ }^{\circledR}$ OpenMP para la computación paralela se ha desarrollado. La metodología propuesta se aplicó al diseño de los paneles compuestos navales y los resultados se compararon con los obtenidos a través de metodologías de diseńo tradicionales. Los resultados muestran un aumento en la confiabilidad de los paneles en todos los casos analizados. El método propuesto se muestra así como una herramienta de ingeniería confiable para optimizar el comportamiento estructural de los diseńos existentes.

Palabras claves: indicadores, medición del desempeńo, cadena de suministros, lógica difusa, Balanced Scorecard, astilleros.

Date Received: October 3rd, 2012 - Fecha de recepción: 3 de Octubre de 2012

Date Accepted: March 4th, 2013 - Fecha de aceptación: 4 de Marzo de 2013

${ }^{1}$ Universidad Tecnológica de Bolívar, Facultad de Ingeniería. Cartagena. Colombia. e-mail: juseche@unitecnologica.edu.co

${ }^{2}$ Universidad Tecnológica de Bolívar, Facultad de Ingeniería. Cartagena. Colombia. e-mail: guillegiraldo@gmail.com 


\section{Introduction}

In recent years, stochastic methods applied to structural design and optimization have gained space because of their robustness and their ability in the search for solutions in complex configuration spaces. This is the case of sea wave loads over naval structures. Likewise, the stochastic nature of mechanical and physical properties of composites require, in many instances, considering them in the design phase.

Composites are increasingly present in naval structural applications. Although their high strength-to-weight ratio represents a very attractive aspect, one of their biggest disadvantages lies on the required ability of the designer to direct the strength and rigidity of the material following the structure's load condition, in such a way that it avails of their mechanical properties (Soremekin, 1997). Thus, by orienting the fibers in each layer of the laminate, a specific design is obtained for a given load set. Thus, performance is not constant along the whole structure, because the areas with higher exposure to high load conditions have better strength and stiffness mechanical properties.

Similarly, the advantages obtained by using composite materials in naval applications are compensated by requiring much more complex structural analysis, where the use of traditional optimization techniques turns out expensive, and in many cases prohibitive, from the point of view of computational costs. Evolutive algorithms are more adequate than traditional optimization techniques for these types of problems because their computational implementation is much simpler.

The present work is framed within the field of structural design, specifically in the determination of the optimal direction of the fibers in a composite laminate plate for naval application, considering in the process the stochastic nature of the sea wave loads. The laminate composite panels are structural elements of broad practical utilization in the design of naval structures, although the complexity of their behavior makes analytical model approximations poorly applicable in practical cases of structural analysis. Thus, to guarantee the safety and functionality of the structures it is necessary to use high design factors. Those design practices tend to yield, as a result, relatively heavy structures.

Using computational tools for structural analysis allows us to overcome this difficulty, but the inclusion of the merit criteria and optimization allow us to go one step further in the quality of the system developed. But impractical tools are equally useless, in spite of how "powerful" they seem to be. Thereby, from the set of possible techniques for simulation and optimization, those considered to allow practical and direct implementation within the context of a design office have been selected.

There are many options at the moment of choosing the merit measurement for a structural design. Among them, the most commonly chosen are minimum weight design, maximum stiffness, or maximum strength. Other alternatives are also possible, like minimization of manufacturing costs, minimization of aero or hydrodynamic resistance, natural resonation frequencies, among others.

This is how the pursuit of the highest strength in a composite laminate panel as a merit criterion in a naval structure is justified by the big impact it has on cargo capacity and optimal strength against sea loads.

\section{Structural Optimization}

Formulating the optimal structural design problem is built in terms of numerical optimization. Under these terms, the minimization problem can be stated as follows:

$$
\begin{aligned}
& \text { Given a set of parameters } x=\left\{x_{i}\right\} \\
& \text { Minimize the function } f(x) \in R \\
& \text { Subject to the restrictions } g_{j} \leq 0
\end{aligned}
$$

That is, search for the set of parameters $x^{*}$ which minimizes the objective function $f(x)$. The set of restrictions, as expressed in the form $1 \mathrm{c}$, is the most general because a restriction in the form $g_{j} \geq 0$ can 
be expressed as $-g_{j} \leq 0$, and an equality restriction $g_{j}=0$ can be expressed as the pair of restrictions $g_{j} \leq 0$ and $g_{j} \geq 0$.

The way in which restrictions are included in the search method seems to be very relevant for its performance. A very elegant and direct way to accomplish this task is the method of the penalty function, as exposed by Parsopoulos and Vrahatis. In this technique, the objective function is augmented with a "penalty" factor $H(x)$, which contains the information from the restriction:

$$
\begin{aligned}
& F(x)=f(x)+H(x) \\
& H(x)=\sum \theta\left(q_{i}(x)\right) q_{i}(x)^{\gamma\left(q_{i}(x)\right)} \\
& q_{i}(x)=\max \left\{g_{i}(x), 0\right\}
\end{aligned}
$$

The term $q_{i}(x)$ is known as the relative violation of the restriction $i$ : for a not violated restriction, $q_{i}=0$, and there is no input to the penalty factor; for a violated restriction $q_{i}=g_{i}$ constitutes a "measurement" of the violation and, in this sense, the task of the functions $\theta\left(q_{i}\right)$ and $\gamma\left(q_{i}\right)$ is to control the input from the violation to the penalty factor.

\section{Particle Swarm Optimization}

The particle swarm optimization method, introduced by Kennedy and Eberhart (1995), is an optimization technique that can be (weakly) categorized am evolutive strategies and, hence, metaheuristics. The technique was originally conceived to simulate the behavior of bird flocks or fish shoals in their search for food. Given that the distance between each individual and the food position is modeled through a function, it was quickly noticed that any function could be minimized by using the technique.

The idea behind the method is the fact that individuals from the population share certain information, which would be the best position found so far (in general terms, the best merit). Each individual uses this information along with the knowledge of its own best position found to guide its search. If the position of an individual $i$ in the search space is $x_{i}$, the best position found so far by the entire population is $x^{g}$ and the best position found by the individual is $x_{i}^{p}$, the search rule is:

$$
\begin{aligned}
& v_{i j}^{k+1}=\left(\omega v_{i j}^{k}+c_{1} r_{1}\left(x_{j}^{g}-x_{i j}^{k}\right)+c_{2} r_{2}\left(x_{i j}^{p}-x_{i j}^{k}\right)\right) \\
& x_{i j}^{k+1}=x_{i j}^{k}+v_{i j}^{k+1}
\end{aligned}
$$

The vector $v_{i}$, from the same class tan the position $x_{i}$, is known as the velocity. The parameters $\omega$, $c_{1}$ and $c_{2}$ are known as inertia, cognition, and confidence because they establish the influence of the current velocity, the distance from the global best, and the distance from the particle best, respectively, over the search rule. Factor $x$ is known as the constriction and its job is to prevent the swarm from exploding by the unbound increment of the velocity. Numbers $r_{1}$ and $r_{2}$ are randomly chosen from the interval $[0,1]$, each time rule 3 is applied. Index $i$ runs over each individual and index $j$ runs over each dimension in the search space. Superindex $k$ runs on each iteration of the search in which $x^{g}$ and $x_{i}^{p}$ are updated based on the merit given by the objective function.

The search rule is applied iteratively until a convergence criterion is met, the desired optimum is found, or we run out of time.

\section{Structural mechanics reliability analysis}

Uncertainty in the analysis and design of naval composite structures has always been recognized. However, traditional approaches simplified the problem by considering the uncertain parameters as deterministic and accounted for the uncertainties by using empirical safety factors. Safety factors are derived based on past experience, but do not absolutely guarantee safety of satisfactory performance (Haldar and Mahadevan, 2000). An alternative way to look at the problem is to consider the stochastic nature of the variables involved in the problem, such as strength, geometrical dimensions, etc. In this case, one might measure the probability of failure to satisfy some performance criterion and the corresponding term would be risk and/or failure probability (Haldar and Mahadevan, 2000). For this reason, naval design guidelines have recently 
been revised to incorporate probabilistic analysis (Ayyub et al., 2000). On the other hand, finite element analysis is a very powerful tool commonly used to analyze complicated structures. It yields good results for a set of assumed values of the variables while ignoring the uncertainty in them. However, the reliability methods currently available can still be used if uncertainty in the response can be tracked in terms of the variation of the basic variables at every step of the deterministic analysis. This concept forms the basis of the stochastic finite element method (Haldar and Mahadevan, 2000).

Several methods with various degrees of complexity have been proposed to estimate the probability of failure (Ditlevsen and Madsen, 2007). In any case, estimating the probability of failure using these techniques requires a background in probability and statistics. But with a simple simulation technique, it is possible to calculate the probability of failure without knowing these analytical techniques (Haldar and Mahadevan, 2000).

The method commonly used for this purpose is called the Monte Carlo Simulation Technique. This technique has six essential elements: (1) Defining the problem in terms of all the random variables; (2) quantifying the probabilistic characteristics of all the random variables in terms of their probability density functions and the corresponding parameters; (3) generating value for these random variables; (4) evaluating the problem deterministically for each set of generalizations of all the random variables, or simply numerical experimentation: (5) extracting probabilistic information from $\mathrm{N}$ such realizations; and (6) determining the accuracy and efficiency of the simulation (Haldar and Mahadevan, 2000). Fig. 1 presents the general procedure used in the finite element stochastic structure.

\section{Composite materials and failure theory}

Composites have one or more discontinuous phases (fibers) embedded in a continuous phase (matrix). The basic element is a composite layer, which coupled to the other forms a laminated structure.
Each layer is reinforced by fibers having a given unidirectional orientation (composites) or may have random orientations (random composites). Compared to isotropic materials, composite materials have a much more complex mechanical behaviour due to their anisotropic nature, which means that a greater number of elastic constants for characterizing their behaviour is required (Kollár, 2003).

The First-Order Shear Deformation theory(FSDT) is an extension of the Kirchhoff-Love theory of laminated plates, where the shear strain is considered in the transverse lamina (Reedy, 2004). This allows taking into account failure by delaminating at the panel.

Fig. 1. Stochastic finite element analysis flowchart

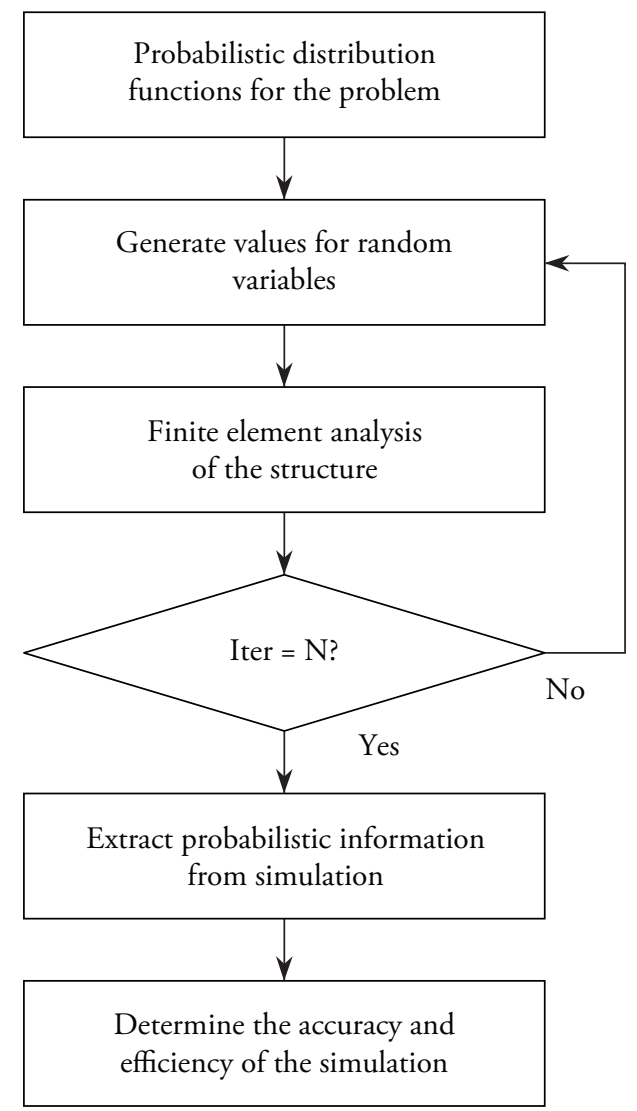

Moreover, one of the most commonly used criteria for failure is the Tsai-Hill composites criterion, based on the failure criteria for anisotropic materials proposed and adapted for failure analysis composites. 
This criterion establishes that the orthotropic sheet subjected to plane strain state occurs when:

$$
f=\frac{\sigma_{11}^{2}}{X^{2}}+\frac{\sigma_{22}^{2}}{Y^{2}}+\frac{\sigma_{11} \sigma_{22}}{X Y}+\frac{\tau_{12}^{2}}{S^{2}}+\frac{\tau_{13}^{2}}{S^{2}}+\frac{\tau_{23}^{2}}{T^{2}}
$$

Where $f$ is known as failure index, $\sigma_{11}, \sigma_{22}, \tau_{12}$, $\tau_{32}$ and $\tau_{13}$ represents components of the normal stresses and shear in the plane 1-2, with respect to the material principal axes; $X, Y$ and $S$ and $T$ represent the normal, transverse and shear failure stress, respectively.

\section{Stochastic optimization methodology}

The pressure distribution on the panel is a function that depends on the space and time variables. This pressure distribution can be obtained directly from experimental data, such as those achieved by the Orca type boat (Useche et al., 2010) or through computer models. In general, pressure distribution on the panel can be expressed mathematically through a function of the type:

$$
P(x, y, t)=H(t) X(x, y)
$$

Where $H(t)$ is a time-dependent function and $X(x, y)$ a function that represents the spatial distribution of the pressure. In this paper, function $H(t)$ is described as:

$$
H(t)=P_{\max }(t / \alpha)^{n} e^{-\frac{t}{\theta}}
$$

Where $P_{\max }$ represents the maximum pressure and $\alpha, \theta, n$ are fitting constants determined experimentally.

The Stochastic design methodology used is presented in the flowchart shown in Fig. 2. The finite element model was developed by using the software for static and dynamic analysis of structures (FEASY/STD $\mathrm{v}^{4} .0^{\circ}$ ) (Useche, 2008). This program was incorporated as an external subroutine in a more general program developed in Python ${ }^{\circ}$ language programming. This methodology was implemented by using parallel programming through Message Passing
Interface (MPI). The module that implements the optimization methodology was developed by Giraldo (2010). Finally, the models were run at the High-Performance Computing Laboratory (HPCLAB) at Universidad Tecnológica de Bolívar.

Fig. 2. Stochastic optimization methodology flowchart

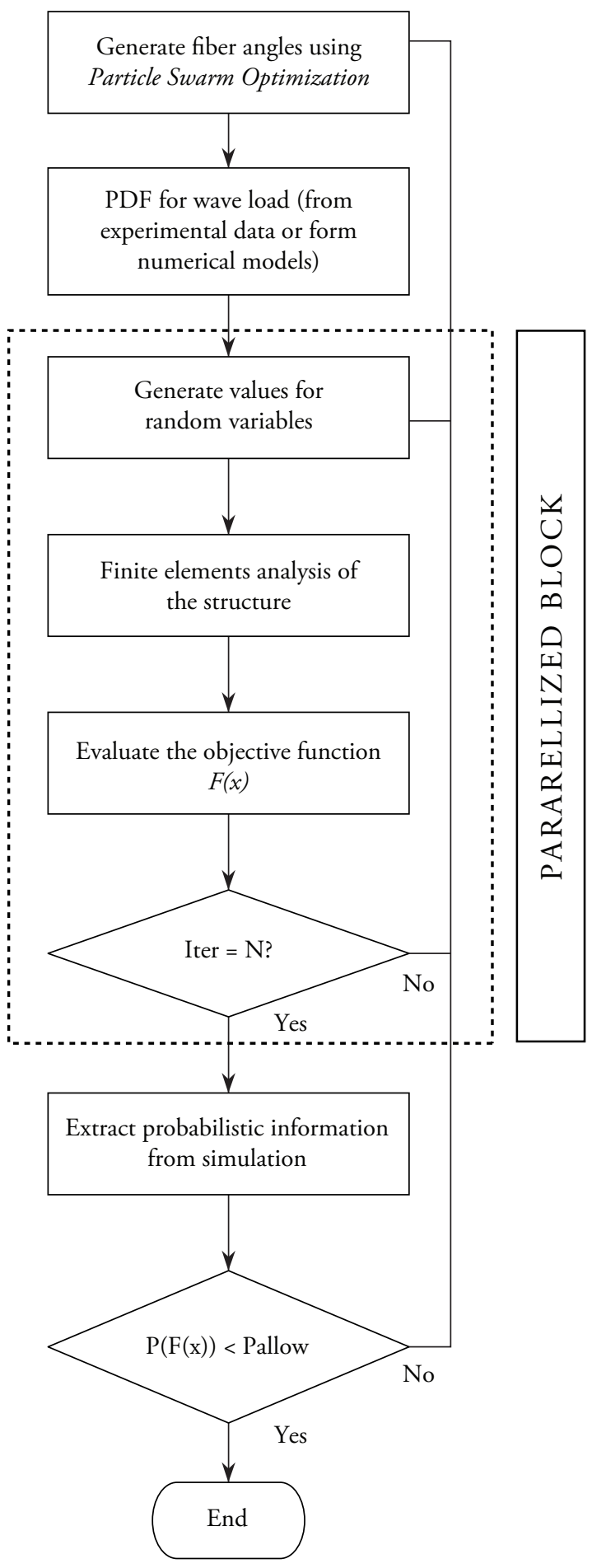




\section{Conclusions}

A methodology was presented to optimize laminated composite naval panels made by using genetic algorithms, stochastic mechanics, and the finite element method. Through minimizing the probabilistic failure criteria of the panel in function of the direction of the fibers in the laminate, it is possible to find designs with high resistance to sea loads for a given system.

\section{Acknowledgements}

The authors are grateful to the High Performance Computing Lab of the Universidad Tecnológica de Bolívar for supporting this research work.

\section{References}

ALLIOT, J., GRUBER, H., JOLY, G. AND SCHOENAUER, M. (1993), "Genetic algorithms for solving air traffic control conflicts". Proceeding of the 9th Conference on AI Applications.

GESTAL, M., (2007), "Introduccion a los algoritmos geneticos", Depto. Tecnologías de la Información y las Comunicaciones, Universidad de la Coruña, España.

GIRALDO, G, (2010), "Método del Enjambre de Partículas y Evolución Diferencial Para el Diseño de Peso Minimo de un Panel Naval Reforzado", Universidad Tecnológica de Bolívar, Trabajo de Grado Ingeniería Mecánica.

HALDAR, A., MAHADEVAN, S., (2000), "Reliability assessment using stochastic finite element analysis", Wyley Editors.

KENNEDY, JAMES; EBERHART, RUSSELL, (1995), "Particle Swarm Optimization", Proceedings of IEEE international conference on neural networks, IEEE, p. 1942-1948.
KOLLÁR, L., (2003) "Mechanics of Composite Structures", Cambridge University Press, UK.

MANEEPAN, K., (2007), "Genetic algorithm based optimisation of FRP composite plates in ship structures", Ph.D. Thesis, Faculty of Engineering, Science and Mathematics, University of Southampton, Southampton.

PARSOPOULOS, KONSTANTINOS E.; VRAHATIS, MICHAEL N., "Particle Swarm Optimization Method for Constrained Optimization Problems", Patras, Greece.

REDDY, J. (2003) "Mechanics of Laminated Composite Plates and Shells: Theory and Analysis", Second Edition, CRC Publications.

REDDY J.N., OCHOA O. (1992), "Finite element analysis of composite laminates", Kluwer Academic Publishers, London.

SOREMEKUN, G. (1997), "Genetic algorithms for composite laminate design and optimization". M.Sc. thesis, Virginia Polytechnic Institute and State University.

USECHE, J., (2008), "FEASYISTD v4.0: Finite element analysis program for linear static and dynamic analysis of solids and structures". Universidad Tecnológica de Bolívar, Cartagena, Colombia.

USECHE, J. BRIX, J., (2009), "Diseño de estructuras navales Fabricadas en compuestos laminados", Reporte de investigación a COTECMAR.

WISNIEWSKI, J., (2004), "Optimal design of reinforcing fibres in multilayer composites using genetic algorithms", Fibres \& Textiles in Eastern Europe Journal, Vol. 12 No. 3(47). 